\title{
Mujer, terapia y resistencia: espacios posibles
}

\author{
María Antonia HIDALGO RUBIO ${ }^{1}$ \\ Universidad Pablo de Olavide \\ mahid@upo.es
}

Recibido: 01/07/13

Aceptado: 21/11/13

\section{RESUMEN}

El impacto de la violencia política en las personas, las familias y las comunidades puede ser muy extenso, como ocurre con el pueblo saharaui, que sufre desde hace 38 años las consecuencias de una ocupación ilegal por parte del gobierno de Marruecos.

La intervención terapéutica común y en especial el arteterapia pueden proporcionar un medio eficaz de expresar, dar sentido y a veces transformar las experiencias resultantes del miedo, la pérdida, la separación, la inestabilidad y turbación desorganización en estos entornos hostiles.

Palabras clave: violencia política, terapia, arteterapia, derechos humanos, población refugiada, ocupación ilegal, Sahara Occidental.

\section{Referencia normalizada}

Hidalgo Rubio, M. A. (2013). "Mujer, terapia y resistencia: espacios posibles". En Arteterapia: Papeles de arteterapia y educación artística para la inclusión social Vol.: 8. Páginas 13-24.

\section{SUMARIO}

Del silenciao a la memoria...Cartas que atraviesan los muros... La creación entre las arenas del olvido. Referencias bibliográficas.

\section{Woman, therapy and resistance: potential spaces}

\begin{abstract}
The impact of political violence on individuals, families and communities can be extensive. As with the Saharawi people, suffering for 38 years the consequences of an illegal occupation by the government of Morocco.

Common therapeutic intervention and especially art therapy can provide an effective means of expressing, making meaning of, and at times transforming the resulting experiences of fear, loss, separation, instability and disruption in these hostile environments.
\end{abstract}

Keywords: political violence, therapy, art therapy, human rights, refugee population, illegal occupation, Western Sahara.

\section{CONTENTS}

From the silence to the memory... Letters crossing the walls.... Creating between the sands of forgetfulness. References.

\footnotetext{
${ }^{1}$ Arteterapeuta. Doctoranda en arteterapia, prácticas artísticas y derechos humanos en zona de conflicto político. Directora del Máster en Arteterapia y Aplicaciones del Arte para el Diálogo y la Integración Social.
} 
...A falta de libertad

hemos tallado un lenguaje, mientras tú nos golpeas, nosotros cosemos banderas, mientras tú desgarras nuestros cuerpos nosotros nos cubrimos de piel nueva mientras levantas muros insolentes, fusilas ojos y gargantas,

a nosotros se nos derrama la voz entre ríos caudalosos de verdades....

Fragmento del poema

En el uso de la palabra, de Salka Embarek

Qué se puede decir, yo era madre y activista, mi vida ha estado llena de dolor,

me tuvieron doce años presa. Doce años. ¿Sabe usted?

Yo perdí a mi bebé estando en la cárcel.

Le amamantaba y entonces me llevaron presa otra vez.

Llegué a prisión y mi leche brotaba para nadie.

Sukeina Yedahlou ${ }^{2}$

\section{DEL SILENCIO A LA MEMORIA...}

Desde 2010 y en la medida que suceda, atiendo como arteterapeuta las secuelas psicológicas que el exilio y la ocupación han ocasionado en la población saharaui. Unas veces, dependiendo del contexto y del tiempo disponible, se hace uso de la práctica artística como lenguaje terapéutico y otras, practico los consejos de Nardone y Watzlawick desde una terapia breve cuyo objetivo es conseguir un alivio sintomático inmediato, en la que la labor terapéutica no consiste en buscar la verdad sino en crear aquellas condiciones de aprendizaje en las que algo distinto, factible y adecuado a la persona pueda ocupar el lugar de esos síntomas y de ese sufrimiento, un llamamiento a una historia constructiva (2003, 175 y ss).

Son ya cuatro años que presto este servicio, principalmente en el marco de ARTifariti $^{3}$, los Encuentros Internacionales de Arte y Derechos Humanos en el Sahara Occidental y en los campamentos de refugiados en Tindouf, un proyecto que surge de la necesidad de dar a conocer la difícil situación en la que vive el

\footnotetext{
${ }^{2}$ Testimonio de Sukeina Yedahlou en la sesión terapéutica que mantuvimos en el Aaiún ocupado. Abril 2012.

3 ARTifariti, ediciones 2010, 2011, 2012 y 2013.
} 
pueblo saharaui y la profunda creencia en el arte como herramienta capaz de generar transformaciones personales y sociales.

Escolares, adolescentes, mujeres, soldados, disminuidos físicos y psíquicos, son varios los colectivos con los que se ha venido trabajando durante estos años, y cuyos objetivos principales han sido:

- Sostener y reforzar la identidad saharaui.

- Facilitar la expresión, primero con uno mismo y luego con el grupo.

- Abrir vías creativas para recomponer la ausencia. Aprovechar el proceso de creación para dinamizar el proceso de construcción y crecimiento personal.

- Disminuir la ansiedad producida por la pérdida y el aislamiento.

- Favorecer el desarrollo de actitudes de resiliencia y las cualidades que favorecen esta capacidad.

- Impulsar el trabajo grupal en un espacio de respeto y escucha del otro.

- Conectar con la propia capacidad de soñar y desear.

Pero la necesidad de acotar el trabajo de campo, ha dirigido mi proyecto de tesis doctoral hacia la intervención terapéutica con familiares de presos y desaparecidos saharauis que viven en los campamentos de Tindouf adscritos a su asociación-FAPREDESA ${ }^{4}$ - y con las víctimas de la represión marroquí en los territorios ocupados.

Ya en 2010 y bajo el título "Bellis perenne, bellas resistentes sin habitación propia: Intervenciones en arteterapia y artes visuales con familiares de presos y desaparecidos saharauis", fue presentada la tesina en la Universidad de Granada, avance de una investigación más extensa que ahora me ocupa.

Bellis perenne es el nombre científico de un tipo de margarita capaz de soportar el calor extremo y cuya infusión aplaca el dolor de las quemaduras. Metafóricamente pensé en esa flor cuando supe que iba a trabajar con mujeres saharauis, cuyo papel es imprescindible para la sociedad y la lucha pacífica de su pueblo, pero sobrecargadas de responsabilidades y con pocas concesiones personales.

Virginia Woolf en "Una habitación propia" (1967, 63 y ss) nos habla de la necesidad del ser humano de encontrar un espacio propio de subjetividad, de

${ }^{4}$ AFAPREDESA es la Asociación de Familiares de Presos y Desaparecidos Saharauis. Nace como respuesta civil a la lamentable situación de los derechos humanos, la incapacidad de defensa de los desaparecidos y torturados y de nuestra angustia como padres, hijos, esposas o hermanos ante la consecuencia de la invasión cívico-militar del Sáhara Occidental por Marruecos.

Se constituyó el 20 de Agosto de 1989 en los Campamentos de refugiados de Tindouf. Es una Organización No Gubernamental saharaui de defensa de los Derechos Humanos, así reconocida por las leyes saharauis.

Es miembro observador de la Comisión Africana de Derechos Humanos y miembro de la Coalición Internacional para la protección de todas las personas contra las desapariciones forzadas. Participa en el Consejo de Derechos Humanos de la ONU en Ginebra. También actúa ante el Parlamento Europeo.

AFAPREDESA ha sido proscrita por el gobierno marroquí, pero aún así continúa ejerciendo su actividad dentro del territorio ocupado. 
expresión singular y de reconocimiento de una existencia. Las sesiones terapéuticas con las mujeres han facilitado simbólicamente la construcción de ese espacio personal donde poder habitar por unas horas, un espacio que se cierra y que a la vez se expande, que se auto revela y se protege continuamente. Un espacio de confianza abierto a lo posible y a lo simbólico, que descubre nuevos sentidos para sostener las fuerzas y generar dinámicas constructivas y saludables.

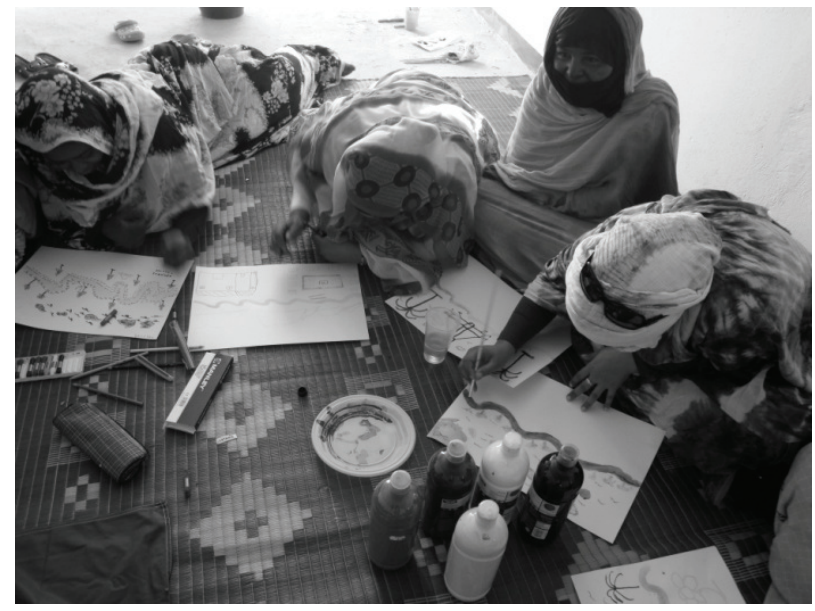

Fig 1. Mujeres del campamento de Auserd en un taller de arteterapia representan el Rio de la Vida, un caudal identitario de la cultura saharaui.

El espacio del arteterapia es algo más que un espacio físico. Se construye como espacio simbólico, como extensión de juego simbólico, donde todo lo que ocurra es tomado como elemento susceptible de reflexión y, por supuesto, de análisis.

Como señalan los arteterapeutas Debra Kalmanowitz y Bobby Lloyd, al entrar en ese espacio, se entra en un terreno de seguridad donde se activa un potencial para reparar preocupaciones y miedos. Toda terapia debe estar contenida dentro de ciertos límites o fronteras, en un marco que la defina como un lugar de experiencia distinto de la cotidianidad, donde el sujeto sabe que es un lugar especial y donde lo que ocurra tiene un significado especial. (2005:23)

\section{CARTAS QUE ATRAVIESAN LOS MUROS....}

El pasado 3 de noviembre de alguna manera preparábamos un "espacio de posibilidad" para recibir a Christopher Ross, secretario general de Naciones Unidas para el Sáhara Occidental en la Sede de la Unión Nacional de Mujeres Saharauis -UNMSde Bojador, antiguo Campamento 27 de Febrero en Tinduf, donde la población saharaui vive refugiada desde hace 38 años. Era un sábado no demasiado caluroso y ARTifariti había finalizado dos días atrás. El grupo de artistas de esta edición ya 
había regresado y sólo quedábamos en los campamentos un pequeño grupo de 7 personas con la intención de concluir algunas tareas pendientes.

En las tres salas principales del centro se exhibían los distintos trabajos realizados por las cooperativas artesanales de mujeres: cerámica, pintura, henna..., así como una muestra de los dibujos de las torturas que los artistas Alonso Gil y Federico Guzmán habían realizado a través de los testimonios de 18 personas víctimas de la represión en los territorios ocupados. Un viaje que realizamos en abril de 2012 por iniciativa de la Asociación de Amistad con el Pueblo Saharaui de Sevilla - AAPSS- para la realización de un Informe sobre las Torturas en el Sahara ocupado, siguiendo el Protocolo de Estambul ${ }^{5}$ y que ha contado con el asesoramiento del experto en Derechos Humanos Carlos Martín Beristain y la experiencia del traumatólogo Antonio Martínez, que cubrió el registro de las lesiones físicas y toda la documentación oficial de denuncia de los hechos ante las autoridades, corriendo a mi cargo el informe de las secuelas psicológicas de la ocupación. Este trabajo le fue entregado a Ross la mañana del pasado 4 de noviembre en su visita a la UNMS.

En una pequeña mesa de la sala se encontraban también las cartas que estas personas, activistas en su mayoría, habían escrito a sus familiares en los campamentos durante la sesión terapéutica que mantuvimos en el Sáhara ocupado.

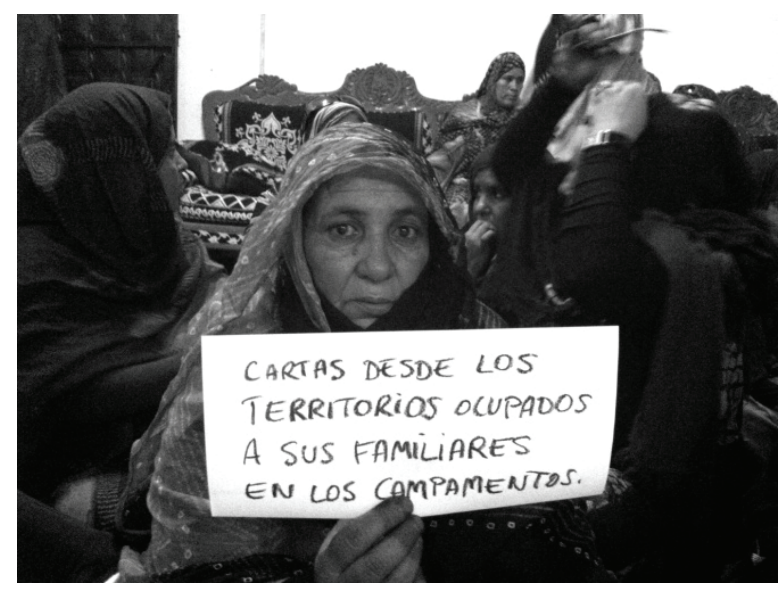

Fig. 2. Familiar de desaparecido. Campamento de Bojador, Tindouf.

"Cartas del otro lado del muro", casi todas acompañadas de algún dibujo, que viajaron conmigo del Sahara Occidental a Andalucía y de ahí a Argel y poste-

\footnotetext{
5 "Protocolo de Estambul. Manual para la investigación y documentación eficaces de la tortura y otros tratos o penas crueles, inhumanos o degradantes". Oficina del Alto Comisariado de las Naciones Unidas para los Derechos Humanos. Ginebra. 2001

${ }^{6}$ Nombre de la acción que se incluye como trabajo de campo en el proyecto de mi tesis doctoral "Arteterapia, prácticas artísticas y Derechos Humanos en zona de conflicto político: el Sáhara Occidental”, en realización.
} 
riormente a Tindouf, 1800 kilómetros vía tierra en un autobús-caravana con 26 artistas argelinos que venían a participar en esta edición de ARTifariti. Después de una intensa búsqueda, esas cartas fueron entregadas personalmente a sus destinatarios en una expectante misión-acción repleta de anécdotas hermosísimas que permanecerán para siempre en nuestra memoria.

Nada más entrar en cada jaima me resultaba sorprendente el poder de la consanguinidad. Los dispositivos de hilos de semejanza entre las familias a uno y otro lado del muro. Aún sin verse durante décadas, cada uno de estos enlaces me transportaba al mismo lugar del espacio terapéutico, con una madre allí y con un hijo ahora, con una hermana y con la otra. Recordaba perfectamente el colorido de sus melfas (vestido tradicional de la mujer saharaui), los pómulos, la mirada complaciente, la forma de llorar, y creo que sus rostros, aún ahora, se podrían identificar sin esfuerzo si se cruzaran en mi camino aquí y en cualquier otra parte. Como el caso de las hermanas Alia y Sukeina Yedahlou, de cuya historia hablaré más adelante.

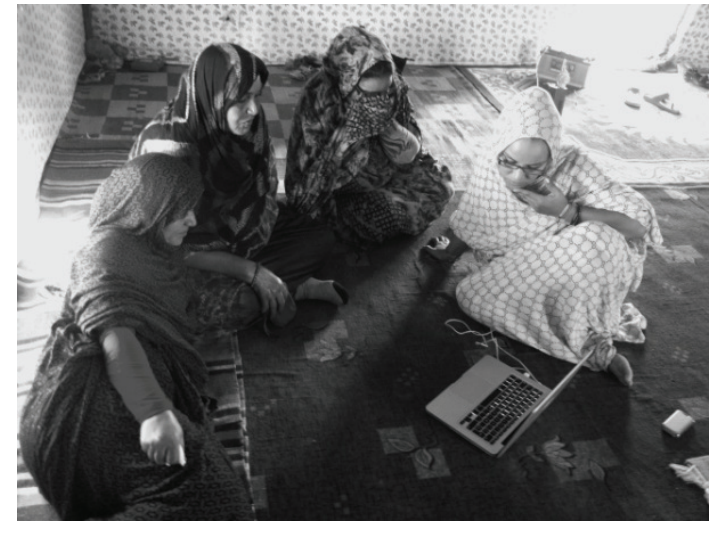

Fig 3. Mujeres del campamento del Aioún oyen los mensajes de sus familiares en el Sáhara ocupado, familias separadas por un muro minado de $2.700 \mathrm{~km}$.

A cada paso, recordaba los encuentros de una hora en los territorios ocupados, sólo una sesión para cada paciente, tiempo verdaderamente reducido para el proceso terapéutico. El lugar, una pequeña "habitación propia", interior y estrecha, próxima a la sala de las entrevistas.

El informe psicológico venía a completar el de carácter general ya existente, por lo que las sesiones habían estado menos centradas en constatar los datos biográficos (ya recogidos en la entrevista previa) y más en proporcionar un espacio de intimidad, de escucha a determinadas cuestiones de carácter más reservado que hubieran podido quedar ocultas, emociones no manifestadas y su planteamiento terapéutico correspondiente.

He podido apreciar en todas las entrevistas que la tortura institucionalizada hace añicos la red social que nos constituye como humanos. Su causa es nítida e identificable, la ocupación marroquí, que convierte a los saharauis en seres acorralados y vulnerables y es la voluntad triunfal y arrogante de los torturadores 
y el estancamiento e invisibilización del conflicto, los dos aspectos que arrojan al pueblo saharaui al sufrimiento interminable, una inscripción psíquica que ya dura generaciones. Es esa zona de secreto y opacidad, lo que llamamos más propio e íntimo "el sí mismo", lo que se ve asediado e invadido en la tortura.

Lo primero que se intentó transmitir es dar confianza y despojar al paciente de cualquier vestigio de culpa, que la tortura no es una enfermedad del torturado sino un mal endémico de la civilización, de una política opresiva que funda su existencia y sobrevivencia en la destrucción del otro. (Madariaga, 2002: 10)

Las sesiones, encaminadas fundamentalmente a aliviar la pena ocasionada por el hecho traumático, cuya tipificación sintomatológica (el diagnóstico que más frecuentemente se asocia a las consecuencias psicológicas de la tortura es el TEPT -Trastorno de Estrés Post-Traumático) que para casos de tortura manifiesta y en este caso de carácter psicológico persistente (el/la saharaui vive la opresión día a día), presenta una serie de características comunes a la mayoría de los entrevistados y que paso a enumerar ${ }^{7}$ :

1. Miedo de que se repita el trauma (tortura), incluyendo la repetición de pensamientos intrusivos concernientes al trauma.

2. Miedo de perder el control de impulsos agresivos, así como la evitación de toda expresión agresiva.

3. Incomodidad acerca de la vulnerabilidad concerniente al fracaso de no haber prevenido el trauma y las dificultades que le siguen.

4. Rabia hacia el origen del trauma y tristeza por la pérdida de otra persona, o por aspectos del yo perdidos por el trauma. Aislamiento. Estancamiento emocional.

5. Quejas psicosomáticas -tensión o dolor en la cabeza, migrañas, síndrome de dolor en la parte baja de la espalda y en las cervicales, úlceras u otras quejas estomacales, hipertensión, alteraciones del sueño, etc.

6. Cambios significativos del estilo de vida y/o confusión concerniente a los valores, dirección y significado de la vida, retirada social (por una parte), y/o equiparar el trauma a un hecho heroico, una autoestimulación, demostrando ante los torturadores/opresores que no tienen miedo (por otra).

Hasta la actualidad y desde 1975 el asedio y acoso de las tropas y administración marroquíes contra la población saharaui ha sido permanente y continua. Organizaciones humanitarias y de defensa de los Derechos Humanos como Amnistía Internacional (AI), la Federación Internacional de Derechos Humanos (FIDH), Human Rigth Watch, la Asociación de Familiares de Presos y Desaparecidos Saharauis (AFAPREDESA) y la Asociación Pro Derechos Humanos de España (APDHE), entre otras, han contabilizado en sus informes cientos de casos de desapariciones forzadas en los territorios ocupados del Sáhara Occidental por

7 Adaptación de "Table 1", pág 233, de Trauma and its Wake, editado por Charles Figley. Tomo I.Brunner/Mazel Psychosocial Stress Series 1985. New York. 
las fuerzas ocupantes del Reino de Marruecos y la Comisión de Derechos Humanos ha expresado reiteradamente su preocupación por los desaparecidos.

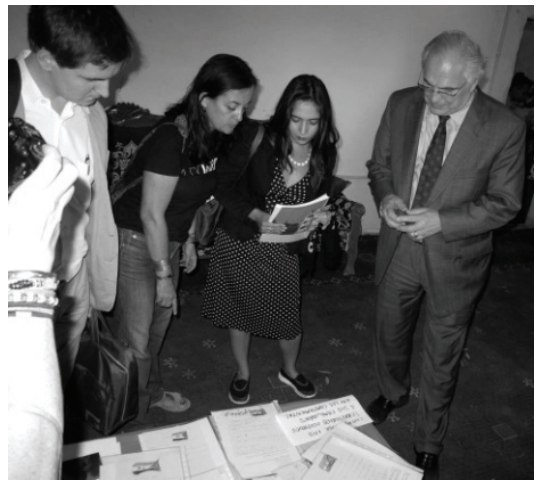

Fig. 4. Chistopher Ross, delegado de Naciones Unidas para el Sahara Occidental, ante las cartas de los activistas de los territorios ocupados a sus familiares en los campamentos. UNMS, Campamento Bojador, 4 nov 2012.

Como afirma el doctor Carlos Martín Beristain ${ }^{8}$ (2012, 95 y ss) las mujeres saharauis han sido quienes mayores consecuencias de la violencia han tenido que enfrentar, tanto por el impacto directo en sus propias vidas como por el hecho de que las consecuencias de la pérdida o el desplazamiento han recaído fundamentalmente en ellas, así como las consecuencias económicas y sociales por el rol que las mujeres tuvieron que asumir en sus familias.

Han sido muchas las mujeres víctimas de desapariciones forzadas, pero aquí me centraré en el caso de Sukeina Yedahlou, de nacida Sukeina El Idrisi (los marroquíes cambian el apellido de nacimiento de las saharauis para desestructurar su identidad), una mujer madura con altos niveles de resiliencia. Quedó sola en los territorios ocupados y entregó su vida a la lucha. Tiene una historia difícil, con pocas concesiones. Doce años torturada en 4 cárceles distintas, la última Qalat Magouna. Perdió a su bebé estando en la cárcel y narra todos los dolores de un parto estéril "murió mi bebé y yo estaba en la cárcel....una consecuencia inevitable cuando se es madre y activista".

Aportó una fotografía de la prisión y no la reconocimos, de una delgadez extrema, una melfa de harapos, "...en esa época sólo comíamos harina y un tipo de aceite".

Cuando pasamos al espacio de la terapia se aprecia un cambio de actitud, una relación transferencial, en la que deja ver sus aspectos más vulnerables. S. Y. tiene bastante control de la auto-imagen y estar con una terapeuta mujer le da confianza. Sabe que es un referente para muchas mujeres saharauis y esa es su

\footnotetext{
${ }^{8}$ Ex- asesor del Tribunal Internacional y experto en Derechos Humanos. Co- autor del informe "El Oasis de la Memoria. Memoria histórica y violaciones de Derechos Humanos en el Sáhara Occidental". UPV y Hegoa, 2012. Beristain nos asesoró para la realización del informe sobre las torturas en los territorios ocupados.
} 
responsabilidad. A medida que la sesión avanzaba se mostraba más relajada, más cómoda.

Menciona dos veces la muerte de su hijo. Así como su divorcio. El precio que ha tenido que pagar por ser activista. "Yo podría haber previsto mi encarcelación... dejé a los niños solos". Intentamos juntas analizar ese sentimiento de culpa como una trampa del mismo sistema opresor y cómo podemos inmunizarnos contra eso. Le explico qué es la inmunización inclusiva (atender los procesos de individualización dentro de la comunidad) y lo importante que es en su caso, ya que tiene sobre sus espaldas parte del peso de la resistencia en los territorios ocupados. Reforzamos el pensamiento positivo.

Llevamos a cabo algunos ejercicios para tomar distancia del hecho traumático y de cómo atender la salud en sus tres aspectos (físico/mental/emocional-social).

Después de algunos años aún somatiza el trauma. Afirma tener dificultades para dormirse y alteraciones en el sueño, a veces pesadillas recurrentes a las agresiones. Practicamos algún ejercicio de relajación para disminuir la ansiedad.

Al terminar la sesión le pregunté si quería escribir alguna carta para sus familiares de los campamentos. Dirigió su texto a Alia, su hermana mayor. En ese momento yo no sabía que era la misma mujer que conocí en octubre de 2010 en uno de los talleres de arteterapia en el campamento del Aaiún, en Tindouf.

Entonces Alia, con profunda tristeza, pedía auxilio a la Comunidad Internacional, le hablaba a la cámara con una angustia moral que nos caló especialmente, pedía por su pueblo, pensando en todo lo que dejó atrás ${ }^{9}$.

Las dos hermanas se han visto recientemente en 2012, en el hospital de Tindouf, donde Sukeina se ha recuperado de las últimas agresiones ocasionadas por la represión marroquí. Constantemente perseguida por ser la presidenta del Forum para el Futuro de la Mujer Saharaui, vive en Smara y tiene una vida muy activa.

La volvimos a ver en su ciudad antes de nuestro regreso a España, iba de negro y pudimos percibir que era un referente en el grupo, una verdadera creadora de "espacios posibles".

Esa creación de espacios facilitadores, ese servicio a la comunidad es sobre lo que ella ha construido su identidad como mujer y lo que ha canalizado su sufrimiento. "Hay que vivir" sostenía continuamente en la sesión. Como decía Virginia Woolf, no se puede encontrar la paz evitando la vida, "you cannot find peace by avoiding life".

En las situaciones donde no hay violencia política y sobreviene el dolor emocional la tarea no es sencillamente sobrevivir, sino también pasar los momentos difíciles y emerger con el deseo de continuar viviendo y seguir creciendo. Nor-

\footnotetext{
${ }^{9}$ El testimonio de Alia viene recogido en el audiovisual "Bellis perenne. Intervenciones en arteterapia y artes visuales con familiares de desaparecidos/as saharauis". Tesina de Máster, Universidad de Granada, Dic. 2010.
} 
malmente intentamos negar los sucesos emocionalmente traumáticos y tendemos a pensar que la desgracia tardará en llegarle a una, si es que ella. En cierta medida, esta actitud de autodefensa es comprensible, pues tratamos de alejarnos de una experiencia terrorífica, o incluso de la idea de que está suceda. (Viñar, 2005)

Pero las mujeres saharauis viven permanentemente en la agresión, el sufrimiento y la pérdida. A eso se suma el encontrarse dentro de una red social que niega la realidad de ese dolor, lo que no ayuda a superarlo en absoluto. Todo lo contrario, obtienen una mayor sensación de alienación y soledad. Cualquier dolor es más intenso si se tiene que experimentar a solas, por eso es importante el espacio de la terapia. "Hay tantas cosas que tenemos que contar, pero ¿Quién nos oye aquí? Aquí estamos en un agujero, vosotros los activistas de derechos humanos tenéis que ir a las zonas ocupadas y contar lo que le está pasando a nuestro pueblo" sostenía Alia Yedahlou en los campamentos a la vez que mostraba su dibujo.

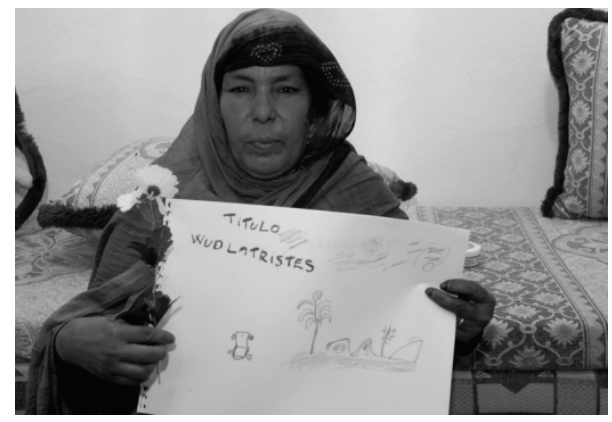

Fig 5. Alia Yedahlou y el dibujo realizado en una de las sesiones titulado "Rio La Tristeza"

\section{LA CREACIÓN ENTRE LAS ARENAS DEL OLVIDO.}

Ver una creación es, de alguna manera, ser invitada a una casa ajena (López Fernández-Cao, 2011, 138 y ss). A nuestra mirada extranjera se impone el espacio del otro. La creación es un lugar de experiencia, para quien la hace y para quien la sabe mirar. La tarea consiste en saber impulsarnos a través de nuestra propia creatividad. Como el varón Munchausen que se salvó de morir ahogado tirando hacia arriba de sus propios cabellos.

La creatividad, que no es otra cosa que el mirar la realidad desde otro lugar, nos proporciona el placer de experienciar, un espacio de exploración, de atrevimiento, de confianza, en el que estamos con nuestros sentidos en conciencia plena, un espacio psíquico de transición que une lo interno y lo externo. Es encontrar ese lugar donde jugábamos de pequeñas, esos paisajes donde la realidad se perdía para ser recuperada y aportarnos un sentimiento de potencialidad y de significación para nosotras mismas y para los otros.

Resulta sorprendente ver cómo el papel en blanco es aquí, en este desierto, una metáfora de la exuberante realidad subjetiva. Se llena de elementos, de color, de formas, permitiendo que entraran en juego muchos elementos: la condensa- 
ción de recuerdos, el desplazamiento, la simbolización y la integración. En el acto de crear y sentir se pasaba de la emoción al pensamiento y a la inversa, volviendo a narrar la historia personal, cada historia de vida para así permitir que disminuyese la escisión, facilitándose una cierta continuidad existencial y poder, en cierta medida, reducir el sufrimiento creando un espacio de acogida para el familiar perdido.

La pérdida aquí es más dolorosa ya que va unida al desconcierto de no saber si este se encuentra vivo o muerto, si su cuerpo habrá sido mutilado, cercenado, ultrajado sin reserva alguna, lo que conlleva una distorsión en el proceso de duelo y la pena profunda de no haber podido llorar un cuerpo, enterrarlo con mimo ni atender su sepultura, haciendo extremadamente vulnerable el recuerdo mismo, que viene asociado sin remedio al desconsuelo.

Alia Yedahlou dibuja un río, y no es el Río de Oro de su infancia en el Sáhara Occidental, es un río seco y se llama La Tristeza. Solicitamos que una mañana magnánime se oigan las voces de un pueblo nómada que no ha sido escuchado, reconvertir ese río y construir sobre su cicatriz un enorme dique capaz de contener todas las lágrimas derramadas, todas las lluvias del desierto que destrozan las casas de adobe, todas las aguas de los partos estériles, toda la saliva de los activistas, y su enorme caudal se impulse constante hacia los territorios liberados, disuelva los muros ${ }^{3}$ y desactive las minas ${ }^{4}$ hasta llegar al mar, donde Alia y Sukeina esperan confiadas la llegada de un nuevo miembro a la familia e intercambian sus melfas.

\section{REFERENCIAS BIBLIOGRÁFICAS}

AFAPREDESA (Asociación de Familiares de Presos y Desaparecidos Saharauis) (2008). Sahara occidental. Persistencia de las violaciones de los derechos humanos de un pueblo. Afapredesa ediciones.

DE LA CORTE, L., BLANCO, A. Y SABUCEDO, J. M. (2004). Psicología y Derechos Humanos. Madrid. Icaria Editores.

KALMANOWITZ, D, Y LLOYD, B. (2005). Art therapy and political violence. New York. Edit. Routledge

\footnotetext{
${ }^{3}$ Un muro de $2.720 \mathrm{Km}$ de longitud, conocido como Muro de la Vergüenza, separa a la población saharaui de los territorios ocupados por Marruecos y los campamentos de refugiados en Tindouf, Argelia. REMMSO Red de Estudios sobre efectos de minas terrestres y muros en el Sahara Occidental. www.remmso.org

${ }^{4}$ La zona del muro contiene más de diez millones de minas antipersonas, ocasionando cada año decenas de muertos y heridos. ASAVIM, Asociación saharaui de víctimas de minas. Con ellos he intervenido como arteterapeuta en esta última edición de ARTifariti.
} 
LÓPEZ FERNÁNDEZ CAO, M. (2011). Memoria, ausencia e identidad. El arte como terapia. Madrid. Eneida ediciones.

MADARIAGA, C. (2002). Trauma psicosocial, transtorno de estrés postraumático y tortura. Santiago, Chile. CINTRAS. Centro de Salud Mental y Derechos Humanos.

MARTÍN-BARÓ, I. (1990). Psicología social de la guerra. Trauma y terapia. San Salvador. UCA Ediciones.

MARTÍN BERINSTAIN, C. Y GONZÁLEZ HIDALGO, E. (2012). El Oasis de la Memoria. Memoria histórica y violaciones de Derechos Humanos en el Sáhara Occidental”. Donostia. San Sebastián. UPV y Hegoa,

NARDONE, G. Y WATZLAWICK, P. (1999) Terapia breve:filosofia y arte. Edit. Herder

OFICINA DEL ALTO COMISARIADO DE LAS NACIONES UNIDAS PARA LOS DERECHOS HUMANOS (2001). Protocolo de Estambul. Manual para la investigación y documentación eficaces de la tortura y otros tratos o penas crueles, inhumanos o degradantes. Ginebra. Naciones Unidas.

QUERO, S. Y BOTELLA, C.(2012). Tratamiento psicológico del estrés postaumático. Castellón. Edit. Universidad Jaime I.

VIDAL, M. (1989). Lo igual y lo distinto en los problemas psicopatológicos ligados a la represión política. Santago, Chile. Edit. CINTRAS. Centro de Salud Mental y Derechos Humanos.

VIÑAR, MARCELO. (2005) Especificidad de la tortura como trauma. Montevideo. IPAC 